\title{
sciendo
}

\section{The impact of the Artificial Intelligence on the accounting profession, a literature's assessment}

\author{
Mirela Simina STANCU \\ Bucharest University of Economic Studies, Bucharest, Romania \\ mihaimirela15@stud.ase.ro \\ Adriana DUȚESCU \\ Bucharest University of Economic Studies, Bucharest, Romania \\ adriana.dutescu@ase.ro
}

\begin{abstract}
Artificial Intelligence is changing the reality of the accounting field, on a rapid way, due to the benefit of improving and reshaping the actual way of performing activities on this domain. Over the years accounting has changed significantly by replacing the work with paper and pencil first with computers, but more importantly with programmes able to decrease time spend on repetitive work that reduce the amount of errors. The interest on Artificial Intelligence solutions in this domain is not new but on the last years researchers become more focused on it. Despite the material progress there seems to be not enough data to support companies' willingness to embed Artificial Intelligence solutions into their accounting activities. Also, an important aspect of this reality is the capability of experts to adapt faster to the new status quo and to acquire the necessary skills to be able to work with Artificial Intelligence solutions and to overcome the fear of losing their jobs. This paper is focusing on understanding the impact of Artificial Intelligence solution in accounting by conducting a qualitative research based on relevant literature review, of the last years. This paper is highlighting the potential changes Artificial Intelligence can bring to the accounting jobs and the necessary steps to be taken in order to prepare for the new jobs, in which Artificial Intelligence solutions will be more present.
\end{abstract}

Keywords: Artificial Intelligence, Accounting profession, Accounting education, Digitalization.

\section{Introduction}

Artificial intelligence (AI) is one of the most important technology for the future, alongside with Internet of Things, cloud computing, blockchain. It is considered the ability of a machine to imitate human actions like communication, decision taken. Some benefits of implanting Artificial Intelligence solutions, such as the possibility of obtaining more accurate results and time saving while processing a large amount of data are already known in different fields of activity. Artificial Intelligence solutions does not represent a new subject for researchers or a common practice for advanced companies in technology but is an interesting topic for study cases, mainly their impact on the accounting filed (Andriosopoulos et.al., 2019).

Accountants are already using the technology in their daily activities to improve the results and reduce the time spend. In this case AI systems implementation will not be an unknown step in their career. But this comes with considerable benefits as achieving objectives using data-driven decision making, can find insights on the results of the business using data analytics and can save significant amount of time, that would normally be spend on repetitive activities (Sutton et. al., 2016).

The role of this paper is to understand the impact digitalization has on the accounting profession from the company management's perspective. This study is focused on understanding the opportunities and challenges brought by AI solutions to the accounting profession, as it is 
disclosed in the specific literature. The present paper represents the first step of a more in-depth research on the AI impact on accounting profession having the aim to help the companies to understand the benefits from these solutions, while keeping the employees motivated to collaborate. It is also the first step in developing a guide for accounting professionals of the best common practices needed to survive on the new work environment (Chukwudi et.al., 2020).

The recent academic interest on the impact of AI in accounting profession is represented by a limited number of studies. On the last years researchers observed the increasingly trend of integrating new AI solutions in the business but in the accounting profession there is still a need for more in depth researchers in this area.

The target audience of this research is represented by the companies willing to implement AI in their accounting activities and by the accounting specialists which will be forced to adapt to the new working conditions. In order to offer help in this scope the objective of this research is to conduct an in-depth analysis of the existing papers about AI in the accounting profession (Chukwuani et. al., 2020).

This paper is organized on the following way: it begins with an overview of the current literature on the impact of AI solutions in the accounting professions. Next section is presenting the implications of AI solutions on accounting profession and the necessary steps to be followed by companies and employees in order to get the best results. In the final part this paper we are disclosing conclusions, study limitations and some directions for a future investigation on the topic.

\section{Literature review}

\section{Artificial Intelligence solutions- an overview}

There is no doubt that the AI solutions for business raise a great interest our days, not to forget some concerns in connection with its potential negative impact in our lives. In recent years this subject become of significant interest for both academics and business environment. AI solutions are far from being completely developed; therefore, creativity and innovation can be embedded in different ways into this project. Beside the impact on the technological way of doing business, the AI solutions will also have a great impact on the organizational culture and on people's professional lives (Gregory, 2019).

\section{The origin of Artificial Intelligence}

The adaptation of Artificial intelligence started decades ago and become present when the companies started to use computers. Artificial intelligence represented in this study is seen as an improvement of the accounting services' quality, due to the possibility of the intelligent systems of over-take human tasks and even to reach decisions independently (Stancheva, 2018).

The field of AI was founded, formally, in 1956 in Hanover, New Hampshire during a conference at Dartmouth College, where it was mentioned for the first time the term artificial intelligence. At that conference the scientists were positive regarding the fast development of Artificial Intelligence, one of them being Marvin Minsky which is the author of a book about AI. (Rosario et. al., 2016).

This evolution was not as expected due to the lack of government funding and the criticizing reports, which caused a stagnation of the research between 1974-1980. After this period in 1980 the British government started to invest in AI solutions in order to compete with Japanese government. After this short recover the interest on AI faced a new winter, between 1987 and 1993 caused by the production of computers and the limited government funding. But after this period 
researches on the filed begin to emerge and on 1997 a computer produced by IBM managed to beat a Russian campion at chess. In 2011 a computer program has won a quiz show (Greenman, 2017).

\section{The concept of Artificial Intelligence}

Finance leaders face a challenge related to AI, one being the definition of the term. EY (Ernst \& Young) provide help to CFO' s, defining AI as an umbrella term, containing automation technologies from the simplest robotic process automation to specialized tools, able to mimic and out-perform in some specific cases human intelligence. On the same study conducted by EY it is described the evolution of technology until AI solutions appeared.

Robotic process automation solutions are represented by rules-based automation, structured data processing and unattended automation.

Cognitive automation solutions are the intermediary step in the evolution from robot process automation and AI and is represented by machine learning, unstructured data processing and human-in-the-loop.

Artificial intelligence solutions are represented by deep learning and decision making, machine reading and vision and natural language processing and generation for example chatbots (Clarence et. al., 2019).

One of Artificial Intelligence subfield is represented by machine learning. This represents the ability of computers to program themselves, taking their own decisions and predictions, using the data they find. An everyday accounting activity is represented by reconciliation procedures, which needs for the moment, the intervention of a human in order to be performed. Using machine learning this activity can be done automatically due to the ability of a machine to perform small logical connections. In this way the time consumed on this task can be used by the accountant to focus more on its consultancy role, using machine learning to add value to his/her services (Duffy, 2018).

\section{Tends-enablers of AI}

$\mathrm{AI}$ is represented by machines able to replicate human cognitive functions such as problem solving and learning. The terms AI and machine learning (ML) are two f the most used subjects our days. ML represents a subfield of AI which drives the most AI's recent progress. ML is defined as the ability of using techniques that makes the computers to learn and improve without being programmed for this. AI and ML are represented by techniques able to learn patterns recognitions which enables them to make predictions used to facilitate decision-making (Russell et. al., 2018).

Looking more in-depth AI and ML had bought also more sophisticated techniques as Natural Language Processing (NPL), which is able to combine linguistics with learning, having the ability of conducting an intelligent analysis using written languages. Systems based on AI and ML enable machines to offer more accurate results than humans, more often in areas with repetitive work.

The increasing interest in using AI is strongly motivated by the powerful and promising decision tools for companies, relevant in different industries. AI can be easily adopted by companies due to four fundament trends.

These fundament trends are represented by the availability of powerful and affordable machines for today's various activities, better algorithms for use, cloud computing and data availability.

The availability of powerful and affordable machines was influenced by the rapid technological advancement, which increased the computing power accompanied with a lower cost 
of computing. The Moore's Law 2, which sustain that a higher computer power will cause a drop on the computing costs, considered by observers a law applicable only until 2020, is describing the future of technology also after 2020 (Clarence et. al., 2019).

The increasing computing power will drastically improve processing speed. Nowadays technology experts have discovered that activities that decade ago needed weeks to be processed, five years ago took only hours and now are performed in minutes. AI has become nowadays rapidly available for implementation, adaptation and use by businesses due to higher affordability, portability and speed (Gotthardt et. al., 2020).

The availability of better algorithms and techniques for use faced great improvement on the last period. The multitude of research focused on advancing and evolving the algorithms behind AI determined the apparition of a vast AI techniques able to solve different problems. The community of developers is growing, and they also designed packages which can be used for free.

Cloud-computing offers to AI a platform to develop, with improved accessibility, that exceeds the space on hardware and storage devices. Companies started to migrate to cloud-based platform and to perform operations directly from the cloud. Cloud providers are integrating AI and ML into their application programming interfaces (API) which can help the business to obtain customized solutions for their problems or for clients. Cloud platforms determine computing power, data storage and graphic processing units (GPU) to be scalable and in this way helps AI and ML algorithms to perform more efficiently, by eliminating the restrictions of hardware (Andiola et. al., 2020).

The data availability nowadays has increased and is not only structed and numerical but also unstructured, represented by text, images and video. Big Data storage system has offered to the organizations the possibility to store and process these data physical or cloud based.

Having the advantage of these trends AI is now on the position from which can change the way accounting specialists works and to revolutionise the accounting industry.

\section{Accounting profession activity evolution}

The activities in the financial filed has grown substantially in the last years and the need to develop financial tools and practices that will increase the chances for more accurate results in banking, investment and insurance products appears to be one major focus of the industry (Mirzaey et. al., 2018).

Starting with 2008, after the financial crisis, a need for the businesses to focus more on financial health at global level emerged and the first two areas to improve were risk management and cost control. In order to support this change accounting departments started to concentrate on delivering better results, within the agreed budget (Smith, 2018).

Finance professionals have increased their representation at the highest levels of the organization's strategic decision-making process, due to their potential of advising business leaders on commercial and technical issues of the business, according to a study conducted in 2020 by UiPath.

Finance and accounting domains started to use new technologies to assure a better relationship with clients but with ought losing the focus on delivering more accurate results, necessary in decision making, risk analysis, controlling and reporting. The way a service is designed, monitored and provided to the client has changed significantly, due to the new regulatory system imposed for financial services (Andrianopoulos et.al., 2019). 


\section{Methodology}

This paper represents the first step of a more in-depth research of the impact of AI on the accounting profession. At this phase we decided to use a specific research approach, by studying the relevant articles and conduct an assessment of the existing literature in order to understand the level of existing information related to the impact of AI on the accounting activities.

In order to conduct this analysis on the existing information we have used the qualitative analysis of the scientific and business literature related to AI impact on accounting activities. This approach is motivated by the scarcity of a clear impact that the AI has on various companies, not to add the limitations disclosure that the AI'S opportunities and challenges providing. The current study aims to understand the perceived impact of AI on accounting field, based upon the scientific and professional affiliations. Further steps in completing this study will be to conduct a qualitative study involving accounting professionals, in order to understand their opinion on the studied topic.

Secondary data for this topic on the scientific filed were found by using the following databases: Taylor, Elsevier and Emerald from which it has been selected 22 articles related to Artificial Intelligence in accounting. While searching for the articles the following key words were used: Artificial intelligence, Artificial intelligence in finance, artificial intelligence in accounting, artificial intelligence in business, digitalization.

\section{Results and discussions}

The Annual Global CEO Survey conducted by PwC ( $22^{\text {nd }}$ edition) disclosed that the utilization of AI will bring 15.7 trillion US\$ to the global GDP until 2030. This represent more than the combined GDP of India and China. The business leaders understood the need of making a change now in order to gain a bigger part of the prize. According to this survey 3 out of 5 global CEO consider future AI impact larger than the internet revolution (PwC Annual Global CEO Survey, 22 ${ }^{\text {nd }}, 2020$ ).

The result of a survey conducted on public accounting professionals by Patrick O'Brien in 2020 analysing the level of utilization of AI, represented by ML and RPA has shown that the accounting profession is already using this technology. The survey also wanted to measure the receptiveness of ninety accounting professionals to this technology as well as the impact of it on their activity.

The result of the study is showing that on the public sector this technology is not used extensively, and the trainings provided to employees are basic (O'Brien, 2020).

Even if they have interacted on a limited level with AI, employees can see, in the last five years, a major change caused by AI in their activity and they are receptive to these changes in their careers. The implementation of AI appears to be strongly correlated with the firm size, while for a big firm the possibilities of implementing AI solutions are easily available, but for small firms these are reduced. On public accounting AI adaptation is not yet performed on a large scale but in the future, it will make substantial changes (O’Brien, 2020).

Even if the accounting profession represents a traditional one, based on rules and principles established long time ago, there is a need for this profession to adapt to the new paradigm. The technology evolution, that is providing solutions for the business, the presence of stronger regulations and globalization are forcing accountants to rapidly adapt to the transformations still coping with the basic accounting principles and rules.

A study conducted by UiPath in 2018 found the challenges faced by organizations on the automatization process, the one related also with accounting activities. These challenges are represented by legacy systems as Oracle E-Business Suite and SAP which started to be 
implemented in 1990s, and due to the resistance to change employees and companies using these systems, generated the need to swich to the new systems. As a consequence, to this more organizations faced issues and delays in implementing AI solutions. On the other side, new-born organizations which started directly to work with the new systems are flexible and willing to implement more digital solutions (Issac et. al, 2018).

The paper-based documents are still present in most accounting activities, i.e. invoices, expense statements, purchase orders. The processing activity of these document is still based on hard copies and requires manual intervention to scan, store and verify the data. The business solutions meant to automize these processes are not very efficient because these is still a need for human intervention within the process (Gulin et.al. 2019).

Other challenges are represented by unstructured data formats, fragmentation and natural language interaction.

The first step taken by businesses in paving the way to AI implantation is to start using robot process automation. The Institute for Robot Process Automation describes this term as the opportunity for employees to configure a computer software to mimic their actions as processing a transaction, operate with data, finding solutions and communicating them to other digital systems.

The implementation of RPA represents a real opportunity for companies which used in the past outsource solutions provided from India and South East Asia. In this way the risks of wrongly processed data or poor customer experience are reduced (Zhang et.al., 2020).

The process of AI solutions development and implementation on the financial services presented a series of challenges. Developing a realistic model and technique which is designed to drive effectiveness faced the high level of uncertainties, which imposed the design of a robust model and more time spend in the testing part. The second disadvantage is the ascending trends of big data usage in financial services, but the lack of a data structure makes them hard to be used. The third issue is represented by the data availability and the necessity of employee's decision support in real time. The transparency of the results is very important, due to their direct correlation with the effectiveness of the internal control (Li et. al., 2018).

The concern of losing the human control, due to the implementation of Artificial Intelligence solutions is a myth, for the accounting profession. AI represents a complement to human intelligence, and this will bring benefits to the accounting profession, enabling the accounting domain to interact better and support more the management functions of the business.

Due to the impact of Artificial Intelligence on the accounting profession it started to appear a real need for a dedicated education in this field and also a change on the curricula in order to assure that the graduates will be better prepared for their future jobs (Stancheva et.al., 2018).

AI will not replace the jobs of accountants, but it will improve their work, by reducing the time spend on repetitive tasks. In order to be prepared to integrate the solutions provided by artificial intelligence into the regular activity's accountants need to focus on developing new skills and abilities.

The first set of skills to be impacted professional skills, every accountant needs to constantly improve his/her professional capabilities throughout their career.

Secondly the focus should be on enhancing the management skills. Even if an accountant will not become manager, if these skills, are available, it will increase the chances to reach a management position when available and wanted.

Computer skills are becoming more and more important in the era of Big Data. An accountant should be able to work not only with regular software, but he/she needs to be highly software literate, in order to easily adapt to the on-going changing business environment. An 
accountant which can understand the logic behind the IT system provides value-added for the IT team working on the development of these solutions.

Analytical skills are important, due to the need to analyse financial information and to correctly evaluate the risks of some actions and decisions, based upon available information.

Decision making skills will help an accountant to correctly evaluate a project's quality and the necessary resources. The finance team should be able to understand the impact of a project for the company, the way competitors are performing similar activities and to be able to support with evidence the decisions making process on a long run or short run (Chukwuani et. al., 2020).

Nowadays companies started to hire accountants which know how to work with information technology, on the top of a good professional education. Being able to use and implement AI in one's work/activity is a competitive advantage that matters.

A survey conducted on 2018 by Cheyenne Whitman, applied to accounting professionals and educators, measured the perception over the AI implementation, together with the associated risks. Young participants to the study considered that AI implementation will reduce time spend on repetitive tasks and improve their work. On the same study the problem of the accounting education was raised, which is not up to date with the new needs from future employees and is not able to prepare the new generation of accountants to adapt to the new reality of jobs (Cheyenne et al., 2018).

Accountants are using technology to improve their activity but using AI will improve the investment decisions and quality of the business. The accounting profession has the chance now, by implementing AI to become a more dynamic and appealing profession, due to the cancellation of human repetitive tasks, that are now taken over by machines, in a more efficient and effective way (Chukwudi et. al. 2020).

On every industry AI has an important impact, and the accounting field is not the exception. AI solutions are helping companies to remain competitive by saving time and money and by finding insights useful for decision making. This will help the companies to get new customers and the attract the new generation of employees which are open and willing to join an organization focused on continuous development.

In 2016 a survey conducted by Narrative Service concluded that $38 \%$ of enterprises are using AI to automate their repetitive tasks and by the end of the year the number is expected to grow to $62 \%$ (Duffy, 2018).

AI is not only about automating repetitive and time-consuming tasks, but it is also about helping the business to mitigate various risks, in connection to cash-flows. AI can predict and monitories the cash flows on the organization, effectively and efficiently (Duffy, 2018).

According to World Economic Forum in 2018 up to 36\% of repetitive tasks on Financial Services were performed by algorithms and machines (World Economic Forum, 2018). The same study found that by 2021 almost $61 \%$ of these repetitive tasks will be performed by machines and most of the jobs related to data entry or bookkeeping will disappear.

Some Financial Institutions are already using AI solutions and machine learning methods to establish credit quality, to automate the interaction with clients, to establish the price of insurance contracts (Financial Stability Board, 2017, p.1).

$\mathrm{AI}$ is also implemented in sectors as banking and finance, were it enhances the area of customer analytics, but also the digital products creation and innovation. There is an interest in fraud prevention and in the solutions of reducing the errors as well. 
Accountants and accounting companies need to focus on developing and strengthening their knowledge on AI and be able to integrate the positive impact of these technologies, into their activities and strategies.

AI will improve accountants' activities if they will be able to work closely with researchers and developers of AI solutions, to design the best product and processes.

While implementing AI solutions companies needs to focus on strengthening cyber-defence systems to be able to protect the systems (Chukwuani et. al., 2020).

The PwC's $2^{\text {nd }}$ Annual Global CEO Survey of 2020 has concluded that AI will displace more jobs than it will create. The CEO's consider AI solutions a way to eliminate human bias, i.e. gender bias. AI it is also considered progressive for the society as a hole and it has the potential to become as smart as humans, if not smarter having an impact on the time-consuming activities and the control of errors. It downsizes is, nevertheless, the replacement of many entry level jobs.

In order to be trusted the AI solutions need to be explained and this is an opportunity for professionals to become more valuable to the company, because they will interpret and explain the better and more accurately the results to management team or clients. AI solutions will cause a higher impact than the internet revolution, forcing specialists in every filed of activity to develop new skills in order to be able to adapt and perform.

From labour force perspective governments need to focus on education in order to help the students to prepare for the new jobs. Governments needs to invest more on AI solutions implantations and on a better education for future generation.

\section{Conclusion}

This study represent a review of 22 scientific papers from well-known databases as Taylor, Elsevier and Emerald representing the scientific field and also studies conducted on the business environment from the last five years, in order to better understand the level of knowledge in the accounting filed related to artificial intelligence on the accounting profession.

The accounting industry needs to understand that AI technologies offers tools to improve the activities performed not to steal jobs even if will reduce the data entry jobs.

The repetitive tasks will be successfully replicated by machines, but the decisions making part will still be the job of the accounting professional. Using AI, the company executives will be able to have relevant data when making decisions, that will have a better efficiency and more reduced risks (Clarence et. al., 2019).

The new generation of accountants needs to have strong accounting knowledge, to be proficient in accounting technologies, to developed high communication skills and to be able to understand and effectively present the data to the management team and clients. These skills and knowledge need to be achieved from their studies. After they will graduate, they need to be prepared for the new job requirements, in order to be able to easily adapt and build a successful career. In the future universities needs to adapt the curriculum to the new business needs and developments, in order to be able to better prepare the students interested in an accounting career.

Even if the previous studies anticipated a decrease in the remuneration of accountants because of the AI implementation, this implementation will create opportunities for accounting professionals to work on a more interesting and challenging environment. The professionals with the right mindset, based upon continuous learning and new skills will be able to have bigger chances for a career development.

But this step needs to be encouraged by companies willing to invest in people's education and jobs security. This is the next most important factor of a successful career of a graduate to 
understand the importance of adapting to the new trends. For the experts on the field with more experience the company's willingness to invest in their education represent a unique factor of retention, and a way to ensure that these employees remain competitive on the labour market.

The limitation of the study was due to the small number of article analysis. Future development will extend the analysis and will integrate these conclusions into a more exhaustive study , aiming to generate the "best practice guide on AI challenges" for the professionals.

\section{References}

Andriosopoulos, D., Michalis, D., Panos, M. P., Zopounidis, C. (2019). Computational approaches and data analytics in financial services: A literature review. Journal of the Operational Research Society, 70(10), 1581-1599M.

Andiola, L.M., Erin, M., Carilyn, N. (2020). Integrating technology and data analytic skills into the acvounting curriculum:Acvounting department leaders' experiences and insights, Journal of Accounting Education.

Bakarich, K.M., O'Brien, P. (2020). The Robots are Coming...But Aren't Here Yet: The Use of Artificial Intelligence Technologies in the Public Accounting Profession, American Accounting Association.

Chukwuani, Nnenna, V., Dr. Amaka, E.M. (2020). Automation of Accounting Process: Impact of Artificial Intelligence, International Journal of Research and Innovation in Social Science (IJRISS), Volume IV, Issue VIII, August 2020, ISSN 2454-6186.

Chukwudi, O.I., Echefu, S. C., Ugwuanyi, Boniface, U., Chukwuani, Victoria, N. (2020). Artificial Intelligence in Accounting Firms, Asian Journal of Economics, Business and Accounting.

Clarence, G., Gary, P., Seow, P.S., Benjamin, L., Yong, M. (2019). Charting the future of accounting, Publisher Singapore CPA Australia Ltd.

Cheyenne, W., Matthew, S., (2018). AI: Ovetrated or the Future of Accounting.

Duffy, E. (2018). Artificial Intelligence and its positive impact on the accounting profession, Accountancy Plus, March 2018.

Financial Stability Board (2017). Artificial intelligence and machine learning in financial services: Market developments and financial stability implications. Retrieved from: http://www. fsb.org/2017/11/artificial-intelligence-and-machine-learning-in-financial-service/.

Gotthardt, M., Koivulaakso, D., Paksoy, O., Saramo, C, Martikainen, M., Othmar, L. (2020). Current State and Challenges in the Implementation of Smart Robotic Process Automation in Accounting and Auditing, Journal of Research in Business, Economics and Management.

Greenman, C. (2017). Exploring the Impact of Artificial Intelligence on the Accounting Profession, Journal of Research in Business, Economics and Management.

Gregory, E.U., Imeofon, I.U., Iniabasi, T.E. (2029). Effect of Artificial Intelligence on tbe Performance of Accounting Operations among Accounting Firms in South East Nigeria, Adian Journal of Economics, Business and Accounting.

Gulin, D., Hladika, M., Valenta, I. (2019). Digitalization and the challenges for accounting profession, Econstor, http://hdl.handle.net/10419/207712.

Issac, E., Muni, R., Desai, K. (2018). Delineated analysis of robotic process automation tools, 2018 Second International Conference on Advances in Electronics, Computer and Communications (ICAECC-2018).

Mirzaey, M., Mohammad, B.J., Hojatpour, Y. (2018). How artificial intelligence is challenging accounting profession, Journal of International Scientific Publications. 
O'Brien, P., Kathleen M. B., (2020), The robots are comming... But aren't here yet:The use of artificiak intelligence technologies in tbe public accounting profession.

PwC's 22 nd Annual Global CEO Survey (2020). CEO's curbed confidence spell caution , https://www.pwc.com/gx/en/ceo-survey/2019/report/pwc-22nd-annual-global-ceosurvey.pdf.

Rosario, A., Brown, L. H., Alexander, K., Appelbaum, D. (2016). Research Ideas for Artificial Intelligence in Auditing: The Formalization of Audit and Workforce Supplementation, Journal of emerging technologies in accounting.

Russell, S., Peter, N. (2018). Artificial Intelligence : A modern Approach, $4^{\text {th }}$ US edition.

Smith, S.S. (2018). Digitization and Financial Reporting - How Technology Innovation May Drive the Shift toward Continuous Accounting, Accounting and Finance Research.

Stuart, R., Peter, N. (2018). Artificial Intelligence: A Modern Approach, Global Edition.

Sutton, S. G., Holt, M., Arnold, V. (2016). "The reports of my death are greatly exaggerated"Artificial intelligence research in accounting. International Journal of Accounting Information Systems, 22, 60-73, doi:10.1016/j.accinf.2016.07.005.

Stancheva, E.P. (2018). How artificial Intelligence is challenging accounting profession, Journal of International Scientific Publications, Economy \& Business, ISSN 1314-7242, Vol. 12.

UiPath (2020). UiPath software robots free employees to do higher value work, Report published by Gartner, Inc.

World Economic Forum (2018). The Future of Jobs Report 2018. Retrieved December 3, 2018 from http://www3.weforum.org/docs/WEF_Future_of_Jobs_2018.pdf.

Whitman, C., Sobczak, M. (2018). AI: Overrated or the Future of Accounting, pubished on Trinity University,Digital Commons @ Trinity, https://digitalcommons.trinity.edu/infolit_usra.

Zhang, Y., Xiong, F., Yi, X., Fan, X., Haifeng, G. (2020). The impact of artificial intelligence and blockchain on the accounting profession, IEEE Access.

DOI: 10.2478/picbe-2021-0070, pp. 749-758, ISSN 2558-9652 |

Proceedings of the $15^{\text {th }}$ International Conference on Business Excellence 2021 